\title{
D(+)-Glyceric Aciduria: Etiology and Clinical Consequences
}

\author{
J. R. BONHAM, T. J. STEPHENSON, K. H. CARPENTER, J. M. RATTENBURY,
}

C. H. CROMBY, R. J. POLLITT, AND D. HULL

\begin{abstract}
Departments of Chemical Pathology [J.R.B., K.H.C., J.M.R.] and Neonatal Screening Laboratory [C.H.C., R.J.P.J. Children's Hospital. Sheffeld SIO 2TH; and Department of Child Heallh IT.J.S., D.H.J. Qtueen's Medical Centre, University of Nottingham NG7 $2 U H$, United Kingdom
\end{abstract}

\begin{abstract}
A family comprising mother, father, and five children is described. Four of the children were found to excrete massive amounts of $D(+)$-glyceric acid in their urine. This was verified by gas chromatography-mass spectrometry and the configuration determined by capillary gas chromatography of $\mathrm{O}$-acetylated menthyl esters. The excretion ranged from 10.8 to $19.9 \mathrm{mmol} / 24 \mathrm{~h}$. The remaining child and the parents showed no evidence of this unisual metabolite. The virtual absence of clinical manifestations in this family was particularly interesting. Only two of the children showed any clinical abnormality and this was limited to mild microcephaly and speech delay; the other two children found to excrete large amounts of $D(+)-$ glycerate were healthy and developmentally normal at $7 \mathrm{y}$ and $9 \mathrm{y}$ of age. There was a marked increase in the excretion rate of $D(+)$-glycerate in response to both oral fructose and serine loading. These results are consistent with a deficiency of $\mathrm{D}(+)$-glycerate kinase and indicate the potentially benign nature of this disorder. (Pediatr Res 28: $38-41,1990)$
\end{abstract}

\section{Abbreviations}

NKH, nonketotic hyperglycinemia

GC, gas chromatography

GCMS, gas chromatography-mass spectrometry

$D(+)$-Glyceric aciduria was originally described by Brandt $e t$ al. (1) in a male child with the clinical features of NKH inchuding severe neurologic impairment, myoclonic jerks, and elevated plasma glycine. The child later died aged $31 / 2$ y. Subsequently, five further reports (2-6) have appeared describing $D(+)$-glyceric aciduria but without elevated plasma glycine or the clinical features of NKH. The symptoms observed in these children have been diverse, including: $I$ ) severe metabolic acidosis from birth and failure to thrive in a child eventually lost to follow up, 2) intermittent vomiting and abdominal distension in a child who died, aged $1 \mathrm{y}, 3$ ) progressive neurologic disease from 3 wk of age including hypotonia, epistotonus, and myoclonic jerks in a child who died at $4 \frac{1}{2}$ y of age, 4) hypotonia, delayed motor development, and recurrent seizures in a child surviving at $51 / 2$ $y, 5)$ delayed motor development, axial hypotonia, and spastic tetraparesis in a surviving child aged 1 y $(6,7)$.

In addition to this clinical diversity, there is considerable dispute about the underlying metabolic defect: Kølvraa et al. (8) postulated a deficiency of $\mathrm{D}(+)$-glycerate dehydrogenase, Duran

Received September 5, 1989; accepted March 7, 1990.

Correspondence: Dr. J. R. Bonharn, Department of Chemical Pathology, Children's Hospital, Western Bank, Sheffield S10 2TH, UK. et al. (5) suggested that the results of loading tests performed on their patient were consistent with triokinase deficiency, and, more recently, Van Schaftingen (6) has demonstrated $\mathrm{D}(+)$ glycerate kinase deficiency in liver biopsy tissue from a child with this disorder.

It is against this confusing background that we have been provided with a unique opportunity to investigate a most unusual family comprising mother, father, and five children, four of whom excrete large amounts of $\mathrm{D}(+)$-glycerate. In this report, we outline the clinical and biochemical findings in these affected children and their response to oral serine and fructose loading. These findings are compared with those described in other cases. The results obtained indicate the likely underlying enzyme defect and the clinical findings lead to a novel conclusion about the long term effects of this disorder.

\section{MATERIALS AND METHODS}

Patients. The Asian family that we describe (Fig. 1) comprises mother $(A)$ and father $(B)$ in consanguinous first cousin marriage, both healthy with no adverse medical history, and five children. These include: $\mathrm{C}$, a 13-y-old boy with mild speech delay and microcephaly but no other abnormalities; E, a healthy 9-y-old girl without previous medical problems; and F, a healthy 7 -y-old girl with no previous medical problems. The index case, $G$, a 5 y-old boy, presented with speech delay and breath-holding attacks leading to seizures. His EEG was normal and, despite microcephaly with a head circumference below the 3 rd centile, computerized tomography in this child revelaed a normal small brain. The speech delay has improved with the help of a bilingual speech therapist. These four children all excrete large amounts of $D(+)$-glyceric acid in their urine. Neither the remaining child, $D$, a healthy 12-y-old girl, nor the parents show any evidence of $\mathrm{D}(+)$-glyceric aciduria. All five children are being educated at a normal school.

Routine clinical chemistry revealed no abnormalities in any family member. Other screening tests for metabolic disease, including amino acids and purines and pyrimidines, were normal.

$G C$. The abnormality in the index case, $\mathrm{G}$, was detected during routine urinary organic acid analysis by capillary GC of trimethylsialylesters formed after repeated extraction with five volumes of ethyl acetate and diethylether. Compounds were identified on the basis of their retention time and later confirmed by GCMS. The optical configuration of the glycerate was established by gas chromatographic separation of $\mathrm{O}$-acetylated menthyl esters $(2)$. The concentration of $D(+)$-glycerate was determined in $G$, the index case, and the other affected siblings by comparison with a $5 \mathrm{mmol} / \mathrm{L}$ aqueous standard using dimethylglutarate as an internal standard.

Oral loading tests. After a 12-h fast, oral loading tests with Lserine (200 mg/ $/ \mathrm{kg}$ for $\mathrm{E}$ and $300 \mathrm{mg} / \mathrm{kg}$ for $\mathrm{G}$ ) and fructose (1 


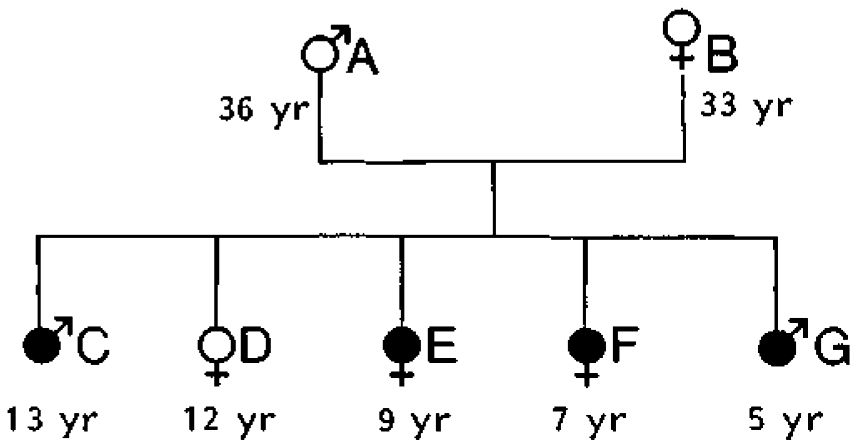

Fig. I. The affected family under study. Family members denoted by closed symbols show marked glyceric aciduria; those represented by open symbols do not excrete $\mathrm{D}(+)$-glycerate. The patient's age is shown in each case.

Table 1. Plasma concentrations and urinary excretion of $D(+)$ glycerate in affected patients

\begin{tabular}{|c|c|c|c|c|}
\hline Patient & $\begin{array}{c}\text { Plasma } \\
\text { concentration } \\
(\mu \mathrm{mol} / \mathrm{L})\end{array}$ & $\begin{array}{c}\text { Urine } \\
\text { concentration } \\
(\mathrm{mmol} / \mathrm{L})\end{array}$ & $\begin{array}{c}\text { Urine } \\
\text { creatinine } \\
\text { (mmol/L) }\end{array}$ & $\begin{array}{c}\text { Excretion } \\
(\mathrm{mmol} / 24 \mathrm{~h})\end{array}$ \\
\hline $\mathrm{C}$ & 186 & 48.6 & 8.3 & $18.0^{*}$ \\
\hline E & 271 & 37.1 & 8.7 & $19.9 \dagger$ \\
\hline $\mathrm{F}$ & 315 & 52.5 & 7.2 & $10.8^{*}$ \\
\hline $\mathrm{G}$ & 191 & 29.0 & 3.8 & 17.44 \\
\hline
\end{tabular}

* Based on 14-h urine collections.

$\uparrow$ Based on 24-h urine collections.

$\mathrm{g} / \mathrm{kg}$ ) were performed on two of the four siblings known to excrete $\mathrm{D}(+)$-glycerate. At the time of the study, patient $\mathrm{E}$ weighed $34.9 \mathrm{~kg}$ and the index case $\mathrm{G}$ weighed $16.5 \mathrm{~kg}$. Timed urine collections were made before and at six hourly intervals after loading. Blood samples were withdrawn at set times after loading to measure glucose, lactate, fructose, and serine concentrations. Fructose in plasma was measured with a Cobas Bio centrifugal analyzer (Roche Products, Welwyn, England) using a modified kit (BCL Ltd., Lewes, England, catalogue no. 139106). Glucose up to a concentration of $10 \mathrm{mmol} / \mathrm{L}$ in the sample did not interfere with the assay. Glucose and lactate were measured by established methods using the Cobas Bio centrifugal analyzer. Serine was quantitated using an automated ion exchange type amino acid analyzer (Biotronik LC500I, Biotech Instruments Ltd., Luton, UK) with ninhydrin detection.

\section{RESULTS}

GCMS analysis. Detection of glycerate on GC was confirmed by GCMS, which showed the molecular mass to be 322 with major fragments at $\mathrm{m} / \mathrm{z}$ values of $307,292,205$, and 189 . The configuration of the glycerate, determined by formation of $\mathrm{O}$ acetylated menthyl esters, was shown to be exclusively in the $\mathrm{D}(+)$ form. The excretion of $\mathrm{D}(+)$-glycerate in the affected children ranged from $29-53 \mathrm{mmol} / \mathrm{L}(10.8-19.9 \mathrm{mmol} / 24 \mathrm{~h})$ before loading (Table 1). The plasma concentration of $\mathrm{D}(+)$-glycerate in affected children is shown in Table 1 and ranged from 186 to $315 \mu \mathrm{mol} / \mathrm{L}$.

Oral loading tests. The effects of oral serine loading on $\mathrm{D}(+)-$ glycerate excretion are shown in Figure 2. There was a marked increase in the rate of excretion of $\mathrm{D}(+)$-glycerate in both patients (2.1-fold for $E$ and 3.3-fold for $G$ ). Plasma serine measured $1 \mathrm{~h}$ after loading rose to $934 \mu \mathrm{mol} / \mathrm{L}$ for $\mathrm{E}$ and $717 \mu \mathrm{mol} / \mathrm{L}$ for $\mathrm{G}$. The incremental increase in $\mathrm{D}(+)$-glycerate excretion in the $12 \mathrm{~h}$ after loading was equivalent to 11 and $39 \%$, respectively, of the serine given.

The response of urinary $\mathrm{D}(+)$-glycerate concentration to oral fructose loading is shown in Figure 3. In both patients, there was a marked increase in the rate of excretion (2,2-fold for $\mathrm{E}$ and

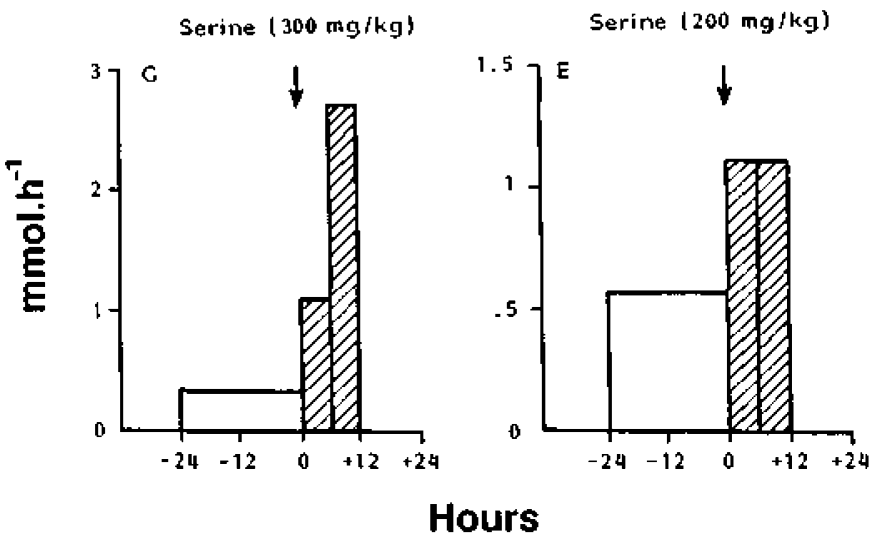

Fig. 2. The rate of urinary excretion of $\mathrm{D}(+)$-glycerate before and after an oral L-serine load is shown for the two patients ( $E$ and $G$ ) studied. The shaded area represents the postload excretion rate.
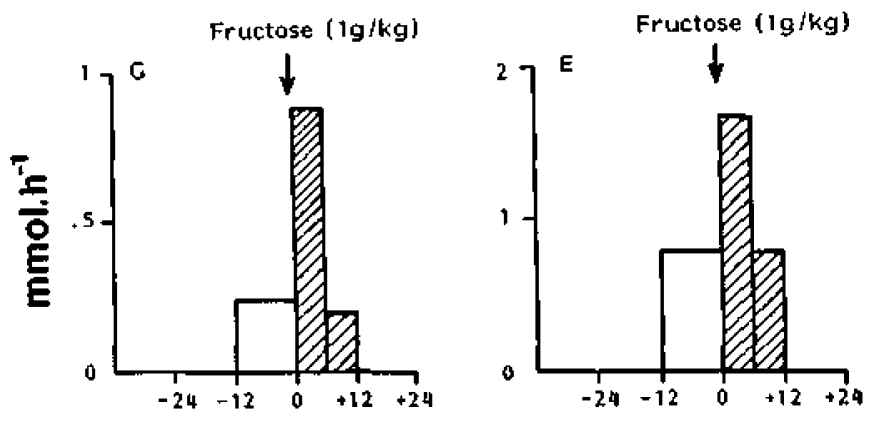

Hours

Fig. 3. The rate of urinary excretion of $D(+)$-glycerate before and after an oral fructose load is shown for the two patients ( $E$ and $G$ ) studied. The shaded area represents the postload excretion rate.

3.6-fold for G). Thirty min after loading, the plasma fructose rose to $0.44 \mathrm{mmol} / \mathrm{L}$ and $0.58 \mathrm{mmol} / \mathrm{L}$ in patients $E$ and $G$, respectively. On a molar basis, approximately 3 and $4 \%$ of the oral fructose could be accounted for by an incremental rise in the excretion of $\mathrm{D}(+)$-glycerate.

The changes in plasma glucose and lactate in response to oral fructose are shown in Figure 4.

\section{DISCUSSION}

The diverse clinical findings described in previous patients ( 1 6) are difficult to reconcile with a single underlying enzyme defect. The original case described by Brandt $e t$ al. (1) with the features of NKH probably represents a distinct metabolic entity. However, the remaining cases form a very heterogeneous group, with $\mathrm{D}(+)$-glycerate excretion as their chief characteristic in common. This suggests three possible alternative explanations. First, that several unrelated enzyme defects have given rise to $D(+)$ glyceric aciduria in different patients. Second, that the same defect has varying degrees of biochemical severity with consequently differing clinical effects. Third, that the findings described in previous patients are unrelated to their symptoms.

The affected members of the family on which we report excrete $D(+)$-glyceric acid in concentrations similar to those observed in previous cases: $12.2-111.6 \mathrm{mmol} / \mathrm{L}$ in this family, compared with $33-187 \mathrm{mmol} / \mathrm{L}$ in the patient investigated by Kølvraa et al. (8), 13-45 mmol/L reported by Fontaine et al. (7), and a maximum of $116 \mathrm{mmol} / \mathrm{L}$ in the patient reported by Wadman et al. (2). The plasma concentration of $\mathrm{D}(+)$-glycerate described in previous cases (7) is also comparable with those found in the present family. It is therefore difficult to explain the mild presentation of our patients by suggesting mild biochemical disease. The occurrence of marked $D(+)$-glyceric aciduria in two healthy 